\title{
Modeling Sustainable Economic Development Using Production Functions
}

\author{
OLEKSANDR YANKOVYI ${ }^{1}$, VIKTOR KOVAL ${ }^{2}$, LARYSA LAZORENKO ${ }^{3}$, OLGA POBEREZHETS ${ }^{4}$, \\ MARINA NOVIKOVA ${ }^{5}$, VIKTORIYA GONCHAR ${ }^{6}$ \\ ${ }^{1}$ Department of Economics of Enterprise and Business Organization, Odessa National Economic University, \\ UKRAINE. \\ ${ }^{2}$ National Academy of Sciences of Ukraine, UKRAINE. E-mail: victor-koval@ukr.net \\ ${ }^{3}$ Department of Management, State University of Telecommunication, UKRAINE. \\ 4,5Department of Accounting and Taxation, Odessa I.I. Mechnikov National University, UKRAINE. \\ ${ }^{6}$ Department of Marketing and Business Administration, Pryazovskyi State Technical University, UKRAINE.
}

\begin{abstract}
The most popular two-factor production functions used in the process of modeling sustainable economic development are examined. Economic and mathematical characteristics of Cobb-Douglas production functions, CES-function, linear function, Leontief and Allen functions are considered, in particular, type of dependence of labour productivity in relation to capital-labour ratio of commodity production system within mentioned production functions. Their most important economic and mathematical characteristics are presented: factors average and marginal return, demand for production resources, factor substitution, factors marginal rate of technical substitution, output elasticity by factors, elasticity of factors technical substitution, optimal capitallabour ratio according to the criterion of maximum output. Comparative analysis is given to Cobb-Douglas and CES-functions, which are two production functions mostly required in practice.
\end{abstract}

Keywords: labour productivity, capital-labour ratio, production functions, sustainable economic development.

JEL Classification: D24, E23, 012 


\section{Introduction.}

COVID-19 pandemic of recent years and associated with it global economic crisis, low payment ability of economic entities, lack of state support complicate economic situation of domestic and foreign enterprises. In these conditions, issues of increasing economic entities' stability and modeling and forecasting their sustainable development has become of great importance. This problem is relevant and its solution largely depends on developing enterprises themselves as well as other market participants.

According to the data collected by Center for Economic and Legal Research and Forecasting [1] in 2019 , industrial production index in Ukraine fell by $0.5 \%$ and reached only $85 \%$ compared to the level in 2013 and $80.7 \%$ to the level in 2011. 2011 was the last peak of industrial growth, because Russian Federation began to take certain restrictive measures against Ukrainian goods in 2012-2013. In fact, in 2020, Ukrainian industry experienced economic decline - in January index of industrial production decline was 5.1\%, in February - 1.5\%. But in March, it received a devastating economy shock because of COVID-19 pandemic and global economic crisis. As a result, in the first half of 2020, industrial production index decreased by $8.3 \%$. Industrial products index in the first half of 2020 was only $80.6 \%$ compared to the level of the first half of 2013 and $77.7 \%$ to the level of the first half of 2011 . Nominal volume of sold industrial products in dollar equivalent in 2019 was only $69,4 \%$ against the level in 2011.

\section{Methodology.}

Studying problems of modeling sustainable development of enterprises in the context of changing internal and external environment is carried out, as a rule, on the basis of various mathematical and statistical models, in particular, using two-factor production functions, which have the following general form:

$$
Y=f(K, L)+\varepsilon,
$$

where $K$ - capital costs; $L$ - labour costs; $\varepsilon$ - random component.

Examples of such two-factor production functions might be such famous economic and mathematical models as Cobb-Douglas function, CES-function (from English abbreviation Constant Elasticity Substitution), linear function, Leontief and Allen functions in their classical and dynamic form $[2 ; 3]$.

Let us point out that result of labour and capital usage within production functions (1) should be measured by the volume of sold, not produced (gross, marketable) products. This approach corresponds to modern views on productivity in market economy: it is necessary to produce only required by customers goods at national and world markets, but not potentially possible goods which might cause problems to sell them in future.

Fixed capital $K$ costs, aimed at acquisition, operation and reproduction of enterprise's fixed assets, are expressed in monetary form, which corresponds to their economic essence. Labour costs can be presented in two main forms: 1) as average number of industrial production staff, or as working hours costs for a certain calendar period (month, quarter, year), expressed in man-days, man-hours; 2 ) in the form of appropriate wage fund (weekly, monthly, annually).

\section{Literature review.}

It is worth mentioning that production functions implementation in the process of modeling sustainable economic development has been considered in the works of many domestic and foreign scientists. Therefore, O. Vilchynska and others [2] studied possibilities of using Cobb-Douglas production function as a tool for managing production resources of the region. B. Grabovetsky and others [3] researched production function usage in modeling economic characteristics of dairy industry. R. Lozinsky, V. Yankovy [4-5] predicted market condition of metallurgical products of 
Ukraine on the basis of Cobb-Douglas production function. I. Sharko, Y. Pashchenko [6] used production function tools to assess effectiveness in case of using resource potential of agricultural enterprises.

Problems of studying elasticity substitution of capital invested in fixed assets and labour were considered by authors [7], who used the CES-function. F. Alvarez-Cuadrado and others [8] considered two-factor production function with known elasticity of labour substitution by capital to assess changes in capital-labour ratio in case of changing marginal rate of substitution. E. Miller's publication [9] is dedicated to analysis of advantages and disadvantages of CES-function and CobbDouglas function while using them for production forecasting. The authors of $[10 ; 11]$ papers consider methodological issues of Cobb-Douglas production function implementation in the problems of forecasting long-term stable state of production depending on two factors: labour and capital. The study of A. and G. Henningsen [12] highlights the most dominant problem in estimating parameters of CES-function, which is related to local minima of objective function.

Despite rather wide discussion in scientific literature on issues of modeling sustainable development of enterprises with the help of production functions, some issues in this area remain unresolved. They include the following problems: type of dependence of labour productivity in relation to capital-labour ratio within particular function, selecting the model describing original empirical observations in the most accurate way, etc. Attempt to solve mentioned problems defined the goal of this paper, which is dedicated to further development of methodological apparatus of production functions implementation in economic researches.

\section{Peculiarities of the most popular production functions used in modeling sustainable economic development}

1. Cobb-Douglas production function. A pioneering scientific paper in the field of practical construction and production function implementation is considered an article issued by P. Douglas and C. Cobb in 1928 [15]. In this paper, the authors, for the first time, clearly mathematically specified and empirically evaluated relationship between output $Y$ and two basic factors - costs of fixed assets $K$ and labour $L$. This dependence was obtained by selecting mathematical function for existing statistical observations.

$$
Y=A K^{\alpha} L^{B},
$$

where $A$ - scale factor $(0<A) ; \alpha, B$ - unknown parameters that reflect output elasticity due to production factors $(0<\alpha<1 ; 0<\beta<1)$.

Thus, J. Tinbergen in the XXth century added traditional Cobb-Douglas production function with factor of "neutral" scientific-technical progress [16]. Here the term "neutral" is understood as action of all factors of scientific-technical progress that are not directly related to the factors of "capital" and "labour". As a result, a new model appeared, which became known as Cobb-Douglas-Tinbergen production function:

$$
Y=A e^{\omega t} K^{\alpha} L^{\beta},
$$

where $\omega$-is growth rate of production $Y$ due to all factors, except $K$ and $L ; t-$ time factor $(t=1,2$, ..., N).

Tinbergen actually dynamized static formula (2), which is suitable to describe, first of all, changing in space variables $Y, K, L$. Whereas production function (3) is completely suitable for approximating data dynamics considering time factor for one and the same market-production system - enterprise, industry, region, country. Scale factor value $A$, generally speaking, characterizes efficiency of studied market-production system: ceteris paribus, the higher integral value $A$, the greater output $Y$ is provided by appropriate producer and vice versa.

Table 1 presents basic economic and mathematical parameters of Cobb-Douglas production function (2). Let us consider type of dependence of labour productivity in relation to capital-labour 
ratio within Cobb-Douglas production function. For production function (2) labour productivity (average return of resource $L$ ) is expressed as follows:

$$
\frac{Y}{L}=\frac{\mathrm{AK}^{\alpha} L^{\beta}}{L}=\frac{A K^{\alpha}}{L^{1-\beta}} .
$$

Without losing generality, we have analyzed the case when capital converges to infinity for linearly homogeneous Cobb-Douglas production function, that means when $\gamma=\alpha+\beta=1$. Let us calculate limit of labour productivity from formula (4), which in this situation takes the form:

$$
\lim _{\frac{K}{L} \rightarrow \infty} \frac{Y}{L}=\lim _{\frac{K}{L} \rightarrow \infty} \frac{A K^{\alpha}}{L^{1-\beta}}=\lim _{\frac{K}{L} \rightarrow \infty} A\left(\frac{K}{L}\right)^{\alpha}=\infty .
$$

\begin{tabular}{|c|c|}
\hline Indicator & $K$ \\
\hline 1. Average return & $\frac{Y}{K}=\frac{\mathrm{AK}^{\alpha} L^{\beta}}{K}=\mathrm{AK}^{\alpha-1} L^{\beta} \quad \frac{Y}{L}=\frac{\mathrm{AK}^{\alpha} L^{\beta}}{L}=\mathrm{AK}^{\alpha} L^{\beta-1}$ \\
\hline 2. Marginal return & $\frac{\partial Y}{\partial L}=A \beta K^{\alpha} L^{\beta-1}$ \\
\hline 3. Output elasticity, $\%$ & $E_{K}=\alpha$ \\
\hline $\begin{array}{l}\text { 4. Demand for production } \\
\text { resources }\end{array}$ & $K=\left(\frac{Y}{A L^{\beta}}\right)^{\frac{1}{\alpha}}$ \\
\hline $\begin{array}{l}\text { 5. Factor substitution (capital-labour } \\
\text { ratio) }\end{array}$ & $\frac{K}{L}=\left(\frac{Y}{A L^{\beta}}\right)^{\frac{1}{\alpha}}: L=A^{-\frac{1}{\alpha}} Y^{\frac{1}{\alpha}} L^{-1-\frac{\beta}{\alpha}}$. \\
\hline $\begin{array}{l}\text { 6. Marginal rate of factor technical } \\
\text { substitution }\end{array}$ & $\operatorname{MRTS}_{L K}=\frac{\beta}{\alpha} \times \frac{K}{L}$ \\
\hline $\begin{array}{l}\text { 7. Elasticity of factors technical } \\
\text { substitution }\end{array}$ & $\sigma=1$ \\
\hline 8. Optimal capital-labour ratio & $\frac{K_{1}}{L_{1}}=\frac{\alpha}{\beta}$ \\
\hline
\end{tabular}

Table 1. Basic economic and mathematical characteristics of Cobb-Douglas production function

Thus, when $\frac{K}{L} \rightarrow \infty$ value $\frac{Y}{L}$ also converges to infinity (Fig. 1), which from economic point of view is not entirely realistic, because in reality labour productivity is always limited. This characteristic of Cobb-Douglas production function is considered to be the second serious disadvantage of economic-mathematical model under study.

Figure 1. Graph of dependence of labour productivity on capital-labour ratio within Cobb-Douglas production

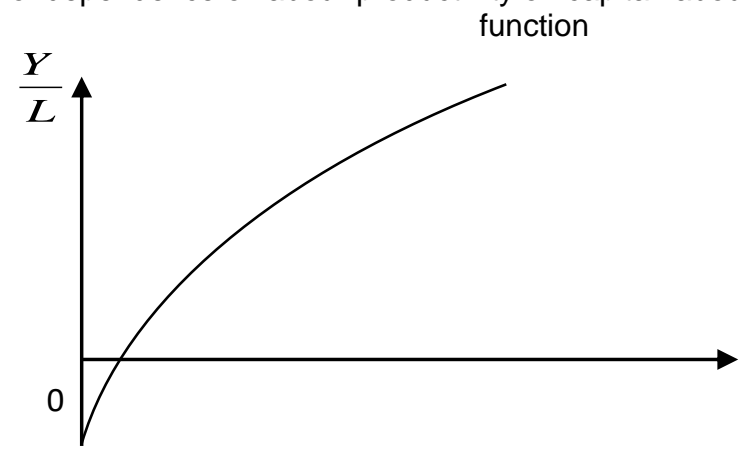


Production functions (2), (3) are substitutional, that is assume certain mutual production factors substitution (elasticity of technical substitution $\sigma_{L K} \neq 0$ ).

It is believed that Cobb-Douglas production function might be used to formalize description of medium-scale facilities (from industrial joint venture to industry), which are characterized by sustainable, stable development. It is though that it is also suitable for analysis of production at the level of country's economy.

2. Function with constant elasticity substitution of factors or CES-function is expressed as follows:

$$
Y=A_{0}\left[A_{1} K^{-p}+\left(1-A_{1}\right) L^{-p}\right]^{-\frac{\gamma}{p}},
$$

where $A_{0}$ - scale factor $\left(0<A_{0}\right) ; A_{1}$ - weighing coefficient of production factor $\left(0<A_{1}<1\right) ; p-$ substitution factor $(-1<p) ; \gamma$ - degree of production function homogeneity $(0<\gamma)$.

In 1961 production function (6) was developed by K. Arrow, Chenery, B. Minhas, and R. Solow based not on the analysis of empirical information compared to Cobb-Douglas function, but as a result of theoretical research of characteristics of future economic-mathematical model [16]. In their paper, authors of CES-function addressed to analysis of elasticity of two-factor functions used at that time. Those existing production functions assumed that elasticity of factor substitution $\sigma_{L K}$ takes fixed numerical value. For example, for Cobb-Douglas production function $\sigma_{L K}=1$. They noted that such restrictions are too strict, which often do not correspond to real economic reality. This argument appeared to be decisive reason for developing generalized function (6), in which elasticity of substitution is also constant, but can take any non-negative values.

Table 2. Basic economic and mathematical characteristics of CES-function

\begin{tabular}{|c|c|}
\hline Indicator & $K$ \\
\hline 1. Average return & $\frac{Y}{K}=A_{0} K^{\gamma-1}\left[A_{1}+\left(1-A_{1}\right)\left(\frac{L}{K}\right)^{-p}\right]^{-\frac{\gamma}{p}} \frac{Y}{L}={ }_{0} L^{\gamma-1}\left[A_{1}\left(\frac{K}{L}\right)^{-p}+\left(1-A_{1}\right)\right]^{-\frac{\gamma}{p}}$ \\
\hline 2. Marginal return & $M P_{L}=\frac{\partial Y}{\partial L}=\frac{\gamma\left(1-A_{1}\right) Y^{1+\frac{p}{\gamma}}}{L^{1+p} A_{0}^{\frac{p}{\gamma}}}$ \\
\hline 3. Output elasticity, \% & $E_{K}=\frac{\gamma A_{1}}{K^{p}}\left(\frac{Y}{A_{0}}\right)^{\frac{p}{\gamma}}$ \\
\hline $\begin{array}{l}\text { 4. Demand for } \\
\text { production resources }\end{array}$ & $K=A_{1}^{\frac{1}{p}}\left[\left(\frac{Y}{A_{0}}\right)^{-\frac{p}{\gamma}}-\left(1-A_{1}\right) L^{-p}\right] L^{-\frac{1}{p}}=\left(1-A_{1}\right)^{\frac{1}{p}}\left[\left(\frac{Y}{A_{0}}\right)^{-\frac{p}{\gamma}}-A_{1} K^{-p}\right]$ \\
\hline $\begin{array}{l}\text { 5. Factor substitution } \\
\text { (capital-labour ratio) }\end{array}$ & $\frac{K}{L}$ \\
\hline $\begin{array}{l}\text { 6. Marginal rate of } \\
\text { factor technical } \\
\text { substitution }\end{array}$ & $\operatorname{MRTS}_{L K}=\frac{1-A_{1}}{A_{1}}\left(\frac{K}{L}\right)^{1+p}$ \\
\hline $\begin{array}{l}\text { 7. Elasticity of factors } \\
\text { technical substitution }\end{array}$ & $\sigma_{L K}=\frac{1}{1+p}$ \\
\hline $\begin{array}{l}\text { 8. Optimal capital- } \\
\text { labour ratio }\end{array}$ & $\frac{K_{1}}{L_{1}}=\left(\frac{A_{1}}{1-A_{1}}\right)^{\frac{1}{1+p}}$ \\
\hline
\end{tabular}

Likewise, Cobb-Douglas-Tinbergen production function, dynamic modification of CES-function has the following form: 


$$
Y=A_{0} e^{\omega t}\left[A_{1} K^{-p}+\left(1-A_{1}\right) L^{-p}\right]^{-\frac{\gamma}{p}} .
$$

Production function (7) might also be used to approximate data dynamics considering time factor for one and the same market-production system - enterprise, industry, region, country. Likewise, production function (2), scale factor value $A_{0}$ of CES-function reflects efficiency of studied marketproduction system. Table 2 presents basic economic and mathematical parameters of CES-function.

Let us analyze type of dependence of labour productivity in relation to capital-labour ratio within linearly homogeneous CES-function:

$$
\frac{Y}{L}=A_{0}\left[A_{1}\left(\frac{K}{L}\right)^{-p}+\left(1-A_{1}\right)\right]^{-\frac{1}{p}}=\frac{A_{0}}{\left[\frac{A_{1}}{\left(\frac{K}{L}\right)^{p}}+\left(1-A_{1}\right)\right]^{\frac{1}{p}}} .
$$

It is obvious that in case $p>0$ where $\frac{K}{L} \rightarrow \infty$ labour productivity in formula (8) in case of any possible values of parameters $A_{0}, A_{1}$ will be limited at the top by value $T$ :

$$
\lim _{\frac{K}{L} \rightarrow \infty} \frac{Y}{L}=\lim _{\frac{K}{L} \rightarrow \infty} \frac{A_{0}}{\left[\frac{A_{1}}{\left(\frac{K}{L}\right)^{p}}+\left(1-A_{1}\right)\right]^{\frac{1}{p}}}=\frac{A_{0}}{\left(1-A_{1}\right)^{\frac{1}{p}}}=T .
$$

Given situation is the most reasonable from economic point of view. Provided $0>p>-1$ where $\frac{K}{L} \rightarrow \infty$ labour productivity in formula (8) in case of any possible values of parameters $A_{0}, A_{1}$ converges to infinity (Fig. 2) like Cobb-Douglas production function.

Figure 2. Graphs of dependence of labour productivity on capital-labour ratio within CES-function

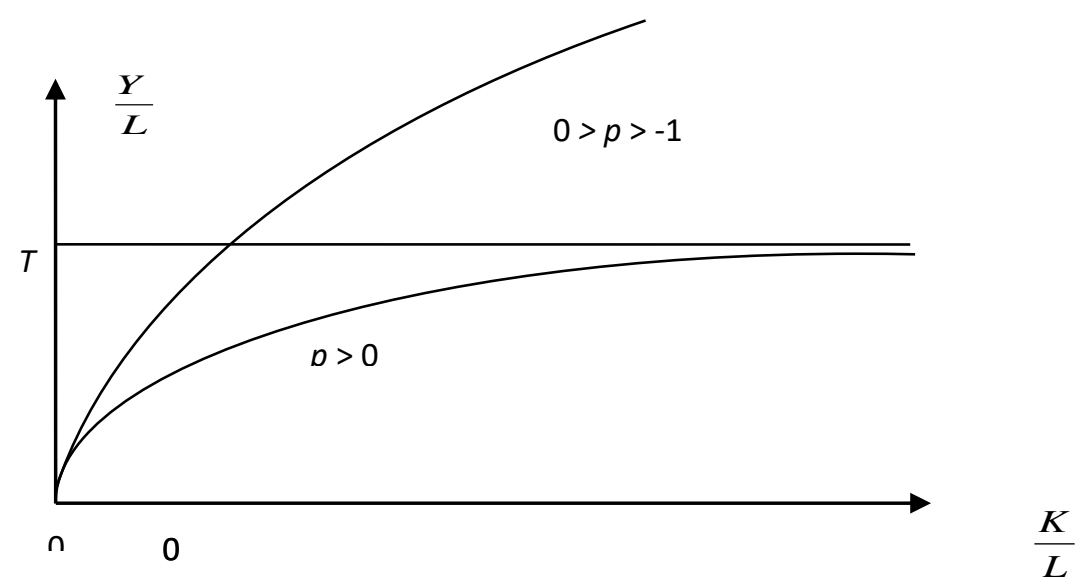


Likewise, Cobb-Douglas production function, CES-function and its dynamical modification are substitution functions $\left(\sigma_{L K} \neq 0\right)$. They are used in case when there is no accurate information about substitutional level of production factors and there is also background to assume that this level is not changed significantly when changing amount of used resources. In other words, economic technology owns certain stability in relation to factors proportions.

3. Linear production function is represented in the following way [17, c. 125-131]:

$$
Y=A_{1} K+A_{2} L,
$$

where $A_{1}, A_{2}$ - are unknown parameters that characterize marginal products of related production factors $\left(0 \leq A_{1} ; 0 \leq A_{2}\right)$.

Homogeneity degree of production function (2.35) $\gamma=1$, which implies that it always remains linearly homogeneous.

Dynamic modification of production function (10), used in modeling time changes of variables, for example, according to statistical reports data of one enterprise for some years period, has the form:

$$
Y=\Delta t+A_{1} K+A_{2} L \text {. }
$$

Model (11) includes additional time factor $t$ (so-called "neutral" scientific-technical progress with unknown average absolute increase $\Delta$ ), which reflects influence on $Y$ of all factors except $K$ and $L$.

Table 3 presents basic economic and mathematical parameters of linear function.

Let us consider type of dependence of labour productivity in relation to capital-labour ratio within linear production function (10):

$$
\frac{Y}{L}=A_{1} \frac{K}{L}+A_{2}
$$

Where

$$
\lim _{\frac{K}{L} \rightarrow \infty} \frac{Y}{L}=\lim _{\frac{K}{L} \rightarrow \infty}\left(A_{1} \frac{K}{L}+A_{2}\right)=\infty .
$$

Therefore, when $\frac{K}{L} \rightarrow \infty$, value $\frac{Y}{L}$ of linear function also converges to infinity (Fig. 3 ) likewise Cobb-Douglas production function. As noted above, from economic point of view, this situation is not entirely reasonable, because in reality productivity is always limited. This characteristic of linear production function is considered as disadvantage of this economic and mathematical model.

Table 3. Basic economic and mathematical characteristics of linear production function

\begin{tabular}{|l|c|c|}
\hline \multicolumn{1}{|c|}{ Indicator } & $K$ & $L$ \\
\hline 1. Average return & $\frac{Y}{K}=A_{1}+A_{2} \frac{L}{K}$ & $\frac{Y}{L}=A_{2}+A_{1} \frac{K}{L}$ \\
\hline 2. Marginal return & $\frac{\partial Y}{\partial K}=A_{1}$ & $\frac{\partial Y}{\partial L}=A_{2}$ \\
\hline $\begin{array}{l}\text { 3. Output elasticity, \% } \\
E_{K}=\frac{K A_{1}}{A_{1} K+A_{2} L}\end{array}$ & $E_{\mathrm{L}}=\frac{L A_{2}}{A_{1} K+A_{2} L}$ \\
\hline $\begin{array}{l}\text { 4. Demand for } \\
\text { production resources }\end{array}$ & $K=\frac{Y-A_{2} L}{A_{1}}$ & $L=\frac{Y-A_{1} K}{A_{2}}$ \\
\hline $\begin{array}{l}\text { 5. Factor substitution } \\
\text { (capital-labour ratio) }\end{array}$ & \multicolumn{2}{|c|}{$\frac{K}{L}=\frac{A_{2}\left(Y-A_{2} L\right)}{A_{1}\left(Y-A_{1} K\right)}$} \\
\hline
\end{tabular}




\begin{tabular}{|l|c|}
\hline $\begin{array}{l}\text { 6. Marginal rate of factor } \\
\text { technical substitution }\end{array}$ & $M R T S_{L K}=\frac{A_{2}}{A_{1}}$ \\
\hline $\begin{array}{l}\text { 7. Elasticity of factors technical } \\
\text { substitution }\end{array}$ & $\sigma_{L K}=\infty$ \\
\hline 8. Optimal capital-labour ratio & $\begin{array}{l}\text { any isocost point } C_{1}=K_{1}+L_{1} \text {, that coincides } \\
\text { with isoquant } Y_{\max } \text { provided } A_{1}=A_{2}\end{array}$ \\
\hline
\end{tabular}

Figure 3. Graph of dependence of labour productivity on capital-labour ratio within linear production function

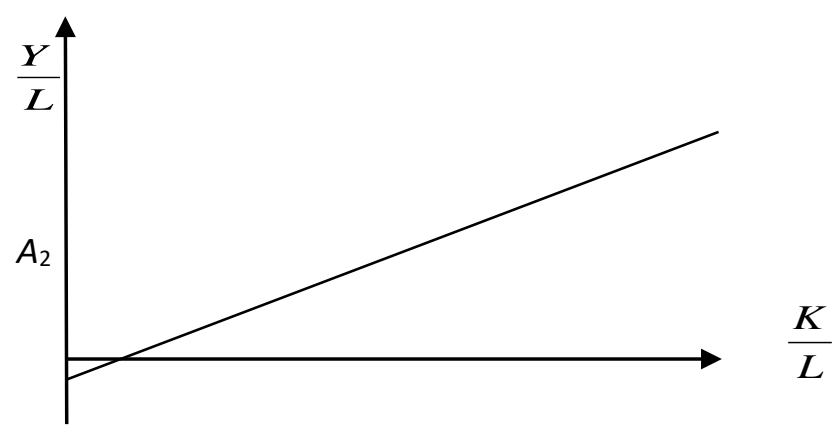

Linear production function provides full resources substitution $\left(\sigma_{L K}=\infty\right)$, which means that output is theoretically possible even when $K=0$, or $L=0$. Therefore, production functions (2.35), (2.36) are absolutely substitute. They are used in modeling of large-scale systems (e.g., industry, region), in which production is the result of simultaneous operation of many different technologies.

4. Function with fixed proportions of factors (Leontief function [17]) is solution to the following problem of mathematical programming:

$$
\begin{gathered}
Y \rightarrow \max , \\
c_{1} Y \leq K \\
c_{2} Y \leq L,
\end{gathered}
$$

where $c_{1}, c_{2}$ - unit costs of relevant factors $\left(0<c_{1}\right.$ - capital intensity of a unit of production, $0<c_{2}$ - labour intensity of a unit of production).

In general, two-factor Leontief production function is written as follows:

$$
Y=\min \left(\frac{K}{c_{1}} ; \frac{L}{c_{2}}\right)
$$

Homogeneity degree of production function (15) $\gamma$ is equal to one.

Table 4 presents basic economic and mathematical parameters of Leontief function.

Table 4. Basic economic and mathematical characteristics of Leontief production function

\begin{tabular}{|l|c|c|}
\hline \multicolumn{1}{|c|}{ Indicator } & $K$ & $L$ \\
\hline 1. Average return & $\frac{Y}{K}=\min \left(\frac{1}{c_{1}} ; \frac{L}{K c_{2}}\right)$ & $\frac{Y}{L}=\min \left(\frac{K}{L c_{1}} ; \frac{1}{c_{2}}\right)$ \\
\hline 2. Marginal return & $\frac{\partial Y}{\partial K}=0$ & $\frac{\partial Y}{\partial L}=0$ \\
\hline $\begin{array}{l}\text { 3. Output elasticity, \% } \\
\text { production resources }\end{array}$ & $E_{K}=0$ & $E_{L}=0$ \\
\hline
\end{tabular}




\begin{tabular}{|l|c|}
\hline $\begin{array}{l}\text { 5. Factor substitution } \\
\text { (capital-labour ratio) }\end{array}$ & $\frac{K}{L}=\frac{c_{1}}{c_{2}}$ \\
\hline $\begin{array}{l}\text { 6. Marginal rate of factor technical } \\
\text { substitution }\end{array}$ & 0 when $K<L ; \infty$ when $K>L ; \frac{c_{2}}{c_{1}}$ when $K=L$ \\
\hline $\begin{array}{l}\text { 7. Elasticity of factors technical } \\
\text { substitution }\end{array}$ & $\sigma_{L K}=0$ \\
\hline $\begin{array}{l}\text { 8. Optimal capital-labour ratio in } \\
\text { case } K=L, c_{1}=c_{2}\end{array}$ & $\frac{K_{1}}{L_{1}}=\frac{c_{1}}{c_{2}}=1$ \\
\hline
\end{tabular}

Let us study type of dependence of labour productivity in relation to the level of capital-labour ratio within Leontief function dividing both parts of formula (15) by $L$, we obtain:

$$
\frac{Y}{L}=\min \left(\frac{K}{L} \times \frac{1}{c_{1}} ; \frac{1}{c_{2}}\right)=\min \left(\frac{K}{L} \times d_{1} ; d_{2}\right),
$$

where $d_{1}=\frac{1}{c_{1}}-$ normative assets return; $d_{2}=\frac{1}{c_{2}}-$ normative labour productivity.

Analysis of expression (16) indicates that at low values of capital-labour ratio, when $\frac{K}{L} \times d_{1}<d_{2}$, its growth is followed by increasing labour productivity. But this phenomenon is observed only to the point $\frac{d_{2}}{d_{1}}=\frac{K_{0}}{L_{0}}$, which is a normative capital-labour ratio (Fig. 4).

Figure 4. Graph of dependence of labour productivity on capital-labour ratio within production function of Leontief

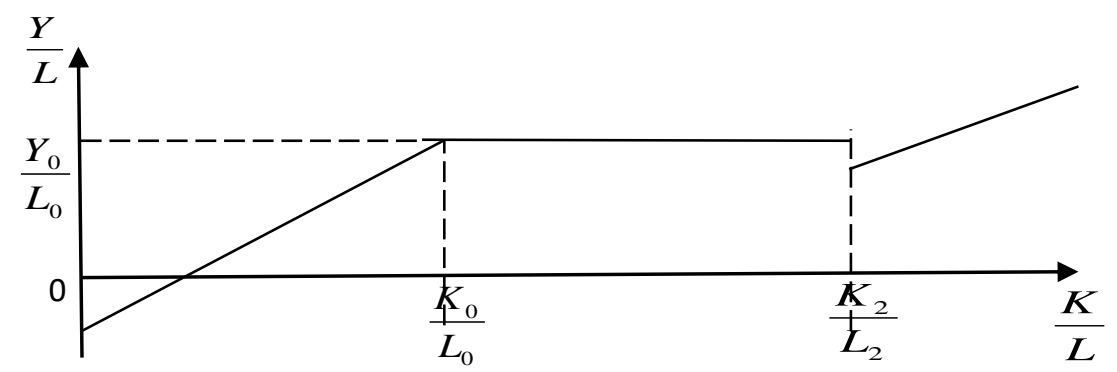

Therefore, in the framework of Leontief production function, in case when capital-labour ratio converges to infinity, labour productivity also converges to infinity. However, this growth partially depends on rationing capital costs on fixed assets and wages. In particular, in case of such rationing absence, labour productivity is not limited from top by fixed normative of labour-output ratio.

Leontief function is strictly limited $\left(\sigma_{L K}=0\right)$, which does not involve substitution of production factors under the condition $Y=$ const. Therefore, it is aimed at modeling defined technical and economic systems that do not allow deviations from technical norms and standards while using resources per unit of output. As a rule, it is used for modeling small-scale or fully automated production facilities.

5. Allen production function has the following form [17]:

$$
Y=A_{0} K L-A_{1} K^{2}-A_{2} L^{2},
$$

where $A_{0}, A_{1}, A_{2}$ - are unknown function parameters $\left(0<A_{0} ; 0<A_{1} ; 0<A_{2}\right)$.

Homogeneity degree of Allen function $y=2$.

Unlike the most popular in economic studies, production functions of Cobb-Douglas and CESfunction, practical implementation of Allen function is quite rare in domestic scientific literature on 
mathematical and statistical modeling and forecasting. Production function is named after R.D. Allen - English economist, mathematician and statistician of the XXth century.

When model is based on empirical data that vary over time (for example, several years at one enterprise), then dynamic Allen production function is used. In this case, production function (17) takes the form:

$$
Y=A_{0} K L-A_{1} K^{2}-A_{2} L^{2}+\Delta t
$$

where $\Delta-$ average annual absolute increase in production $Y$ due to all production factors except $K$ and $L$.

Table 5 presents basic economic and mathematical parameters of Allen function.

Table 5. Basic economic and mathematical characteristics of Allen production function

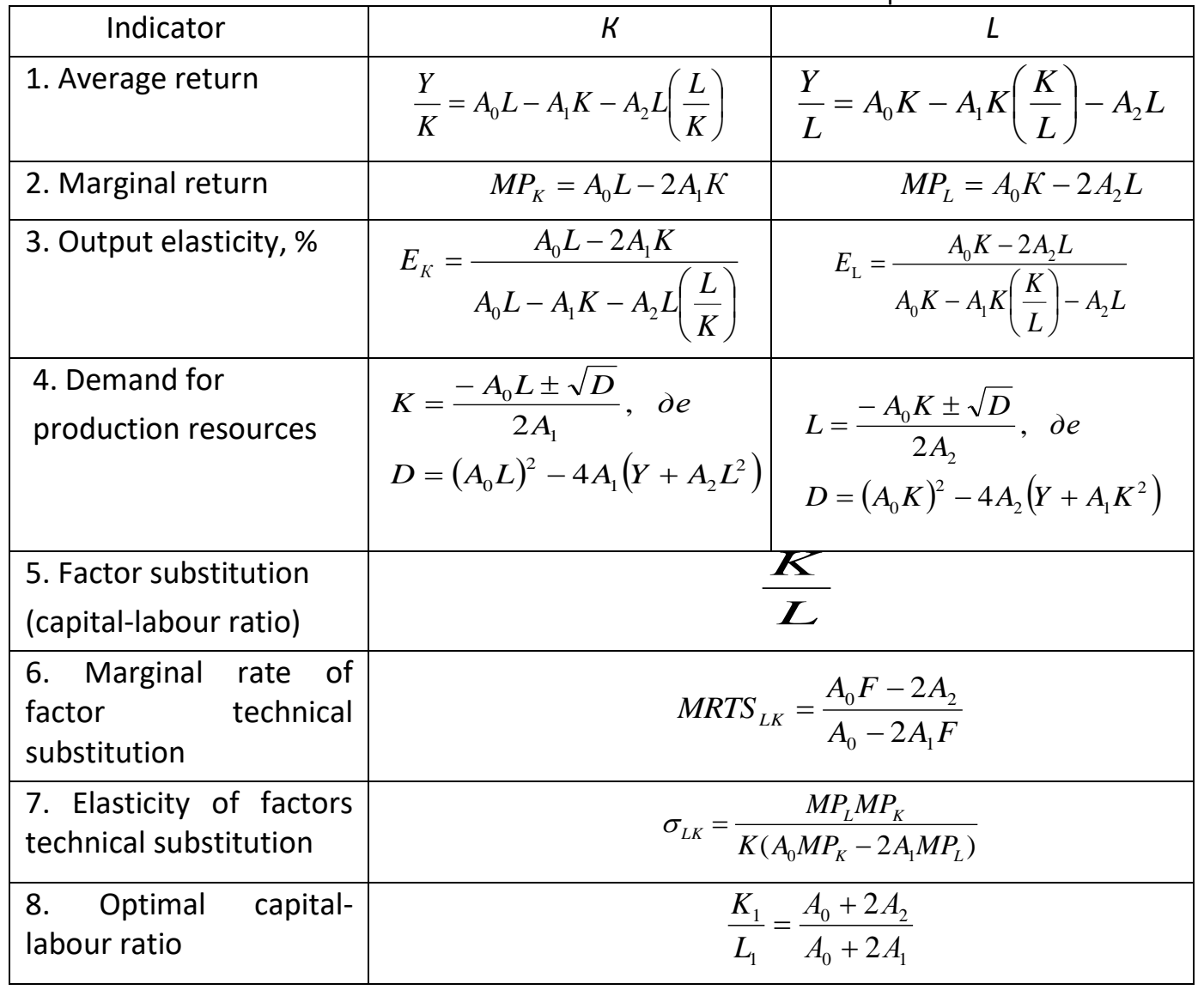

Let us consider type of dependence of labour productivity in relation to capital-labour ratio within Allen production function. To do this, by means of elementary transformations we derive the following formula from expression (17):

$$
\frac{Y}{L}=L\left[A_{0} \frac{K}{L}-A_{1}\left(\frac{K}{L}\right)^{2}-A_{2}\right]
$$

Therefore, relation (19) shows that labour productivity within Allen production function multiplicatively depends on two factors:

1) linearly from labour costs, that means from material encouragement of labour productivity;

2) curvilinearly from capital-labour ratio (parabola of the 2 nd degree).

Let us consider limit of labour productivity when capital-labour ratio converges straight to infinity. Expression (19) means that searched limit depends on coefficients values of parabola of the 2 nd 
degree in relation to capital-labour ratio. Since higher coefficient is $-A_{1}<0$, parabola branches are directed downwards.

Points of parabola intersection with the axis $\frac{K}{L}$, when labour productivity $\frac{Y}{L}=0$ is found by solving the equation

$$
A_{0} \frac{K}{L}-A_{1}\left(\frac{K}{L}\right)^{2}-A_{2}=0
$$

In the process of solving quadratic equation a discriminant is found: $D=A_{0}{ }^{2}-4 A_{1} A_{2}$, which determines number of quadratic equation roots. And in this case three situations are possible.

1. If $D<0\left(A_{0}{ }^{2}<4 A_{1} A_{2}\right)$, then equation (20) has no solutions, and, therefore, parabola has no points of intersection with $\mathrm{X}$-axis. The point of parabola intersection (20) with $\mathrm{Y}$-axis is equal $-A_{2}$. In this situation, graph of dependence of labour productivity on capital-labour ratio looks roughly as shown in Fig. 5.

Figure 5. Graph of parabola (20) providing $-A_{1}<0 ; A_{0}^{2}<4 A_{1} A_{2}$

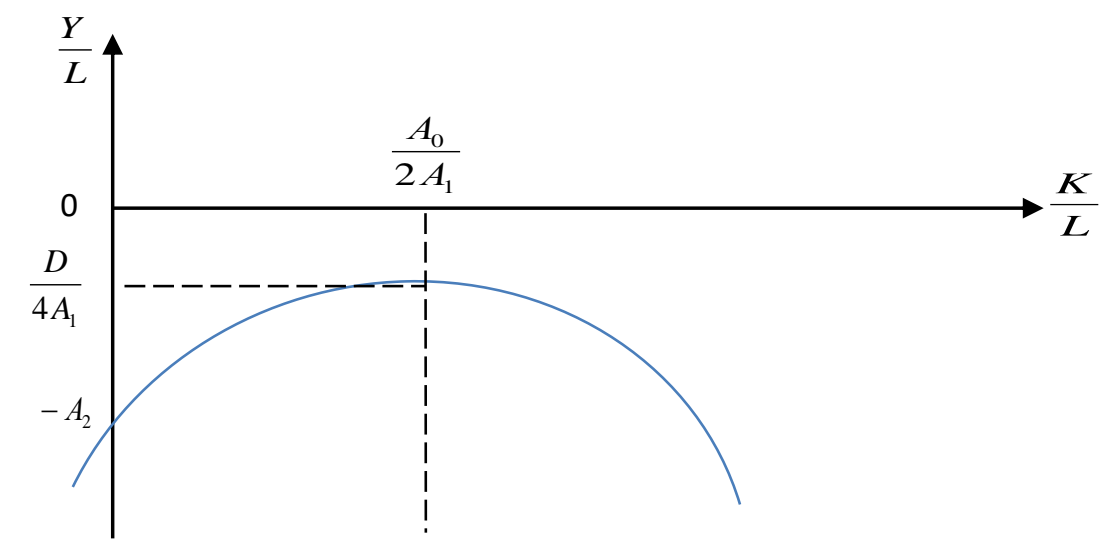

2. If $D=0\left(A_{0}^{2}=4 A_{1} A_{2}\right)$, then equation (20) has one solution and parabola is tangent to $\mathrm{X}$-axis. This case is illustrated by graph in Fig. 6 .

Figure 6. Graph of parabola (20) providing $-A_{1}<0 ; A_{0}^{2}=4 A_{1} A_{2}$

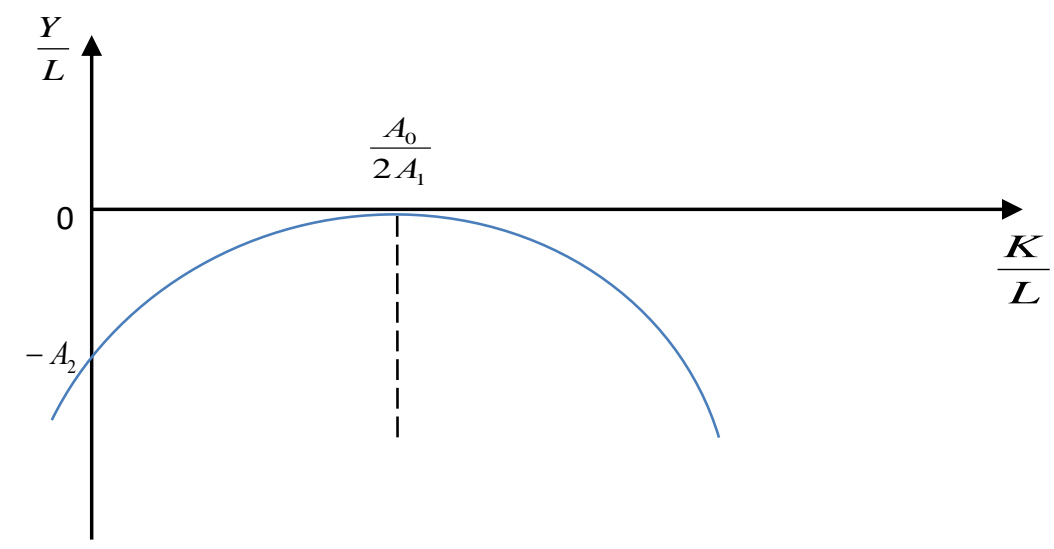

3. If $D>0\left(A_{0}{ }^{2}>4 A_{1} A_{2}\right)$, then equation (20) has two solutions, and parabola has two points of intersection with $\mathrm{X}$-axis. In this situation, graph looks roughly as shown in Fig. 7. 
It is obvious that studying sustainable economic development, based on Allen production function usage, is characterized by the third case, when labour productivity firstly increases together with capital-labour ratio (segment $\left[0 ; \frac{A_{0}}{2 A_{1}}\right]$ ) to value $\frac{D}{4 A_{1}}$ with following decline to zero (segment $\left[\frac{A_{0}}{2 A_{1}}\right.$; $\left.\frac{A_{0}+\sqrt{D}}{2 A_{1}}\right]$ ) and further to minus infinity. That is, within production function (17) when $\frac{K}{\boldsymbol{L}} \rightarrow \infty \frac{Y}{L} \rightarrow-$ $\infty$. Level of optimal capital ratio is optimal from the point of view of maximizing labour productivity. $\frac{A_{0}}{2 A_{1}}$

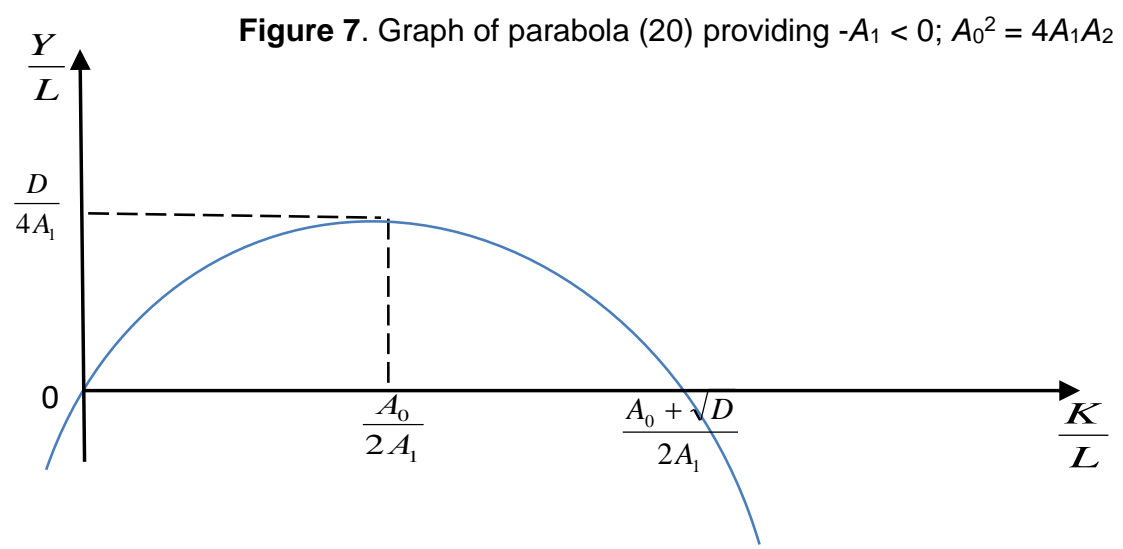

Allen function and its dynamical modification are substitution functions $\left(\sigma_{L K} \neq 0\right)$. Considered higher type of dependence of labour productivity in relation to capital-labour ratio allows to state that production functions (17), (18) are aimed at formalized description of production processes for sustainable economic development of enterprises.

\section{Results.}

Carried out study of economic and mathematical characteristics of above mentioned five production functions showed that the most popular of them are Cobb-Douglas function and CESfunction, which are most often used in modeling sustainable economic development. It has been proved by facts that, depending on value of substitution factor $p$ (elasticity of factors technical substitution $\left.\sigma_{L K}\right), C E S$-function generalizes Cobb-Douglas production function, linear and Leontief functions. Thus, when $p \rightarrow-1\left(\sigma_{L K} \rightarrow \infty\right)$ CES-function converges to linear function where parameter $p$ $\rightarrow 0\left(\sigma_{L K} \rightarrow 1\right)$, production function (6) converges to Cobb-Douglas production function and when $p \rightarrow$ $\infty\left(\sigma_{L K} \rightarrow 0\right)$ it modifies into Leontief's function.

However, it should be kept in mind that linear function and Leontief function due to their specific characteristics (entire substitution of resource factors in the first case and their entire absence in the second one) make these production functions much less implemented compared to Cobb-Douglas production functions and CES-function. The latter are moderately substitute functions, because of their conditions $\sigma_{L K} \neq \infty, \sigma_{L K} \neq 0$. Therefore, their demand in the process of modeling sustainable economic development is predominant and researchers often face problem selecting between these two economic and mathematical models in practice. It is obvious that choosing between CESfunction and Cobb-Douglas production function many factors should be considered, and, first of all, adequacy degree of each of them to market-economic system under study, ability to estimate their unknown parameters easily, clarity of qualitative economic interpretation of found factors, etc. (Table 6).

As far as the first and second characteristics concerns, there is a significant advantage on the side of CES-function. Many economists consider unlimited type of dependence of labour productivity in relation to capital-labour ratio within Cobb-Douglas production function in the foreseeable future utopian and unrealistic. And principal disadvantage of production function (2) and its dynamic 
modification (3) is called hypothesis of single elasticity of factors substitution at all points of empirical observation of market-production system. In this respect, CES-function, whose parameter $\sigma_{L K}$ might take any non-negative value, seems to be more flexible and adequate to economic realities.

Table 6. Basic economic and mathematical peculiarities of CES-function and Cobb-Douglas production function

\begin{tabular}{|c|c|c|}
\hline Peculiarity & $\begin{array}{c}\text { Cobb-Douglas } \\
\text { production function }\end{array}$ & CES-function \\
\hline $\begin{array}{c}\text { 1. Type of dependence of } \\
\text { labour productivity in relation } \\
\text { to capital-labour ratio }\end{array}$ & unlimited & $0 \leq \sigma_{L K} \leq \infty$ \\
\hline $\begin{array}{c}\text { 2. Elasticity of factors technical } \\
\text { substitution }\end{array}$ & $\sigma_{L K}=1$ & it is possible to obtain \\
\hline $\begin{array}{c}\text { 3. Ability to obtain accurate } \\
\text { estimation of unknown } \\
\text { parameters }\end{array}$ & $\begin{array}{c}\text { there is simple way to } \\
\text { get accurate estimation } \\
\text { by data logarithm }\end{array}$ & $\begin{array}{c}\text { atatimation by } \\
\text { datan conting and logarithm }\end{array}$ \\
\hline
\end{tabular}

The third characteristic gives priority to Cobb-Douglas production function. The thing is that CESfunction is fundamentally impossible to be reduced to linear form by logarithm, so there is no exact mathematical method for defining its unknown parameters $A_{0}, A_{1}, p, \gamma$. Approximate computational procedures are used to estimate them, for example, minimization of model residue function by Marquardt method, which requires special software.

\section{Conclusions.}

Review of the most popular charecteristics of production functions used in economic research has revealed specifics and peculiarities of Cobb-Douglas function, CES-function, linear function, Leontief and Allen functions in their traditional and dynamic variants. Carried out study provides researchers in the field of modeling sustainable economic development with profound argumentation to prioritize practical implementation of production functions (6) compared to production functions (2). However, in reality the most popular is Cobb-Douglas production function.

In our opinion, there are several reasons why, despite obvious disadvantages, production function (2) occupies leading position compared to CES-function in modern economic and mathematical modeling of sustainable economic development. First of all, it concerns great number of researchers' ignorance in production functions (6) advantages. In particular, it is related to the fact about their complience to real economic phenomena and processes. In addition, important role in these functions usage is played by lack of large number of observations selecting tools - spatial or temporal data on variables $Y, K, L$. As well as, especially significant selecting factor in favour of Cobb-Douglas production function is simplicity of obtaining estimation of its unknown parameters.

\section{References}

1. Federation of Employers of Ukraine (2020). State of industry in Ukraine. Online available from https://fru.ua/images/doc/analitics/Stan_promyslovosti_1-2020.pdf

2. Vilchynska, O. M. Panochyshyn, Yu. M., \& Kushnir, T. O. (2016). Determination of opportunities of Cobb-Douglas production function as a management tool of the regional production resources. Scientific journal Herald of Khmelnytskyi National University, 2(1), 177-181.

3. Hrabovetskyi, B. Y., Tarasiuk, N. M., \& Bezsmertna, O. V. (2013). The use of production functions in the research companies in the dairy industry. Visnyk of Vinnytsia Politechnical Institute, 5, 3236. Online available from https://visnyk.vntu.edu.ua/index.php/visnyk/article/view/1029

4. Lozinskyi, R. Yankovyi, V. (2018). Forecasting the market of metallurgical production of Ukraine on the basis of production function. Scientific Bulletin of the Odessa National Economic University, 5(257), 174-190.

5. Yankovyi, O., Goncharov, Yu., Koval, V., \& Lositska, T. (2019). Optimization of the capital-labor 
ratio on the basis of production functions in the economic model of production. Naukovyi Visnyk Natsionalnoho Hirnychoho Universytetu, 4, 134-140.

6. Sharko, I. O. Pashchenko, Yu. V. (2012). Application of the apparatus of production functions for evaluation of efficiency of use of resource potential of agricultural enterprises. Innovatsiyna ekonomika, 11, 60-64.

7. Daniels G., \& Kakar V. (2017). Economic Growth and the CES Production Function with Human Capital Economics. Economics Bulletin. 37(2), 930-951.

8. Alvarez-Cuadrado, F., Van Long, N., \& Poschke, M. (2017). Capital-labor substitution, structural change, and growth. Theoretical Economics, 12(3), 1229-1266. DOI : 10.3982/te2106

9. Miller, E. (2008). An assessment of CES and Cobb-Douglas production functions. Washington, D.C. Congressional Budget Office.

10.Goonatilake, R. (2014). Impacts of Labor and Capital on Manufacturing Production Function. British Journal of Economics. Management \& Trade, 4, 158-172. DOI : 10.9734/bjemt/2014/5619

11.Xianbai Li. (2008). The Cobb-Douglas Production Function, Costs, Factor Quantity Employed and Parametric Estimation: A Firm Level Perspective. Journal of Beijing Institute of Technology, 10(6), 70-76.

12. Henningsen, A., \& Henningsen, G. (2012). On Estimation of the CES Production Function Revisited. Economics Letters, 115, 67-69. DOI: 10.1016/j.econlet.2011.12.007

13.Cobb, C. W., \& Dauglas, P. H. (1928). Theory of Poduction. American Economic Review. Sypplement, 139-165.

14.Arrow, K. J., Chenerry, H. B., Minhas, B. S., \& Solow R. M. (1961). Capital-Labor Substitution and Economic Efficiency. The Review of Economics and Statistics, 43(3), 225-250.

15.Yankovyi, V. O. (2018). Optimal capital adequacy and production functions. Odesa, Atlant.

16.Tinbergen, J. (1956). Economic Policy: Principles and Design. Books (Jan Tinbergen). NorthHolland. Online available from http://hdl.handle.net/1765/16740 